\title{
EN EL TRANSCURSO. \\ REFLEXIONES SOBRE LITERATURA ARGENTINA CONTEMPORÁNEA
}

\author{
POR \\ Edgardo H. BERG ${ }^{1}$ \\ Universidad Nacional de Mar del Plata
}

A Joca que supo ver en la entrega de una cita nuestro dilema crítico

Desde Ezequiel Martínez Estrada, pasando por Jorge Luis Borges, Nicolás Rosa, Josefina Ludmer, Juan José Saer o Ricardo Piglia, para nombrar algunos nombres propios, la literatura argentina siempre se ha pensado por fuera de liturgias y cánones más o menos convencionales; más aún, ya sea partiendo de los géneros o atravesando su propia constitución ha sido vista, en más de una ocasion, y desde distintas modulaciones e inflexiones críticas, bajo la incertidumbre de su forma, siempre inacabada y por hacer, acanónica, podríamos decir con Mijaíl Bajtín. Ya sea postulando la extranjería radical de nuestra literatura (donde la literatura gauchesca y los relatos de los viajeros ingleses son la cara y la cruz de una misma letra), o pervirtiendo la intempestiva oposición estradiana (literatura nacional/literatura argentina) bajo el magisterio de Gramsci, al oponer lo estadual (cuyo germen tendría claros visos coloniales) con la formación paulatina de un grupo de escrituras nacionales (en forma de islotes o archipiélagos) que erosionan el peso de la ley (la ley del género, la ley del Estado, entre otras) y subvierten la frontera en tanto determinación de una comarca, constituyéndose en una zona o región intersticial (así pues se talla la idea de lo paraxial como ángulo de luz que irradia la barroca escritura transplatina de Nicolás Rosa). O bien, para hablar de algunas formulaciones más conocidas, sea por caso Borges, que adelantándose como lector avant-garde a Gilles Deleuze o prefigurando sus fieles y no tan fieles discípulos, cuando postula la respuesta política de la literatura argentina, una literatura siempre menor, quiero decir descentrada e irreverente de los cánones y crestomatías occidentales; y más acá Piglia, uniendo la política borgeana con los usos nacionales de los géneros, retomando así, si se quiere, al heterodoxo borgeano que fue Rodolfo Walsh junto a la

\footnotetext{
Profesor Adjunto de Literatura y Cultura Argentinas I y II e Investigador del Centro de Letras Hispanoamericanas de la Facultad de Humanidades de la Universidad Nacional de Mar del Plata, Argentina.
} 
voz oracular y por momentos nietzscheana de Martínez Estrada (Hudson es para Estrada lo que Gombrowicz es para Piglia, para decirlo brevemente). O Juan José Saer y sus hipótesis de una literatura sin atributos, en su mención devota y admirativa de Robert Musil. Un Saer nunca del todo ponderado por la crítica en sus ensayos literarios y que quizás habría que leerlos junto a su exquisita y discreta poesía (en voz baja como la de Juan L. Ortiz), sus experimentales y breves narraciones o sus novelas (esas que fundaron una comunidad regida por la amistad y el diálogo); quiero decir esos ensayos saereanos deberían ser pensados como fluentes o recodos de un mismo río (claro está como sabemos, nunca volveremos del mismo modo al atravesarlo o nunca será el mismo, luego de habernos sentado y escuchado, casi al pasar, el lento crepitar de la leña frente al río, sobre el gaucho o campero viento del convite literario).

Quisiera proponer una hipótesis de lectura rápida. Un debate posible si me permiten. Juan José Saer, en estos últimos años, ha venido a ocupar en los debates críticos y en las vindicaciones o impugnaciones de las escrituras actuales el lugar que antaño ocupaba Jorge Luis Borges. No tiene, claro está, la forma de un debate sesentista, de voz estentórea y altisonante que en cada gesto de escritura o libelo muestra y demuestra su ideología (pensemos en el griterío de alta voz en David Viñas y en la juvenil y no tan juvenil desacralización contornista de Borges impregnada por la prosa sartrista y los estertores mundiales de la Nueva Izquierda); más bien en su resolución escrituraria, la polémica toma prestada ciertas formas actuales de la cultura de masas (las inflexiones y los tics linguísticos del nuevo periodismo deportivo, en formato Olé, cierta construcción de escenas propias de los reality shows, o regulaciones argumentativas y narrativas cercanas al falso documental o a la crónica biográfica no autorizada en su versión Mucht Music). No estoy hablando de intensidades ni de potencias de escritura, ni tampoco de un escritor (Saer) que supo dialogar con los efectos de la escritura borgeana (más allá de los registros o el peculiar uso de los géneros en cada uno, ni del punto y ni la proliferación, ni de la in-tensidad y la extensión) y pudo escribir las novelas que Borges dejaba de lado. Más bien, estoy tratando de pensar cómo Saer es visto por sus contemporáneos, ya sea como un sedimento de posibles proyeccciones literarias o como un nombre propio condenado históricamente a los proyectos modernos y acorralado por una ideología de la literatura cercana a una poética negativa (aquí Adorno suele ser una perfecta llave o ganzúa que los críticos usan a destajo para clausurar su proyecto de escritura enfrentada a la cultura de masas); o en su certera demonización, un producto narrativo tan artificial y gastado como la lucha por imponerlo como un cánon indispensable de la literatura argentina (pensemos en la obstinada riña sin cuartel más tarde o más temprano de Gramuglio, Piglia, Rosa y Sarlo y de las revistas que cobijaron algunas notas de abigarrada defensa, me refiero obviamente a la revista Los Libros y a su continuación Punto de Vista). Curioso destino en la contemporaneidad de alguien que tardó décadas en ser leído y que siempre se mantuvo aparte y ajeno a los modelos literarios establecidos.

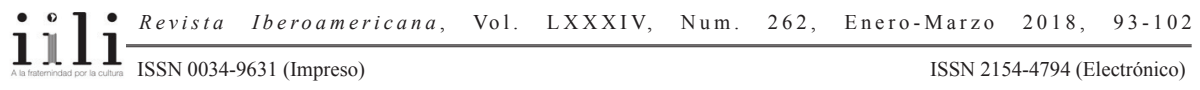


En este sentido, quisiera verbalizar una serie de asociaciones y desplazamientos que podrían funcionar como hipótesis rápidas de investigación o como instantáneas de conocimiento. Voy a tomar dos relatos breves. Ambos relatos, tienen una sintaxis dispar y contrapuesta, sin embargo, son co-ocurrentes en su objeto de destino. Un texto por momentos miope, otro a veces oblicuo. Se trata en un primer caso de leer un texto sobre un plano liso y sin ramificaciones, resolviendo la intriga por el trueque nominal o la rúbrica numismática intercambiable. Y cuando el relato no tenga más que decir, porque las palabras enmudecen, se emborrachan o indigestan después de tanta satírica cata, bien viene a cerrar con una canción y si es un blues mejor. En el otro caso, habría que seguir el curso del río saereano y detenerse en sus meandros, ramificaciones o deslices. Y las pisadas errantes de los personajes bien podrían pensarse en correlación con las advenedizas y excéntricas peregrinaciones que en su recorrido reclama el relato. Se podría decir de liturgias devotas o exhumaciones violentas estamos hablando.

El primer relato es "Casa con diez pinos"de Fabián Casas y pertenece al volumen Los Lemmings y otros (2005). ${ }^{2}$ La crítica más reciente, salvando algunos desmedidos esfuerzos locales, ha vinculado la producción poética de Casas (sea poesía, sea narrativa) con una serie de obras de escritores surgidos en los noventa y que han hecho de la vindicación de Ricardo Zelarayán y del distanciamiento o devaluación de la obra de Saer una proclama o un estandarte político. El ingreso en los debates críticos todavía hoy, salvo raras excepciones decíamos, no ha sabido preguntarse de qué modo ingresa o cómo se lee la producción del escritor entrerriano, autor entre otros textos de "La gran salina" del libro La obsesión del espacio (1972), La piel de caballo (1974-1975) o Roña criolla (1984). Una poesía y una prosa polirítmica que hace ingresar una política del habla (bables locales, regionales o de clase) a partir de los contrapuntos y ritmos entrecortados muy cercana a la experimentación formal de la vanguardia y bajo el aura lacaniana del grupo Literal de los setenta. Y en muchos casos, se ha mantenido, más bien, como una suerte de política del nombre propio o como una moneda intercambiable de la devaluada obra de Juan José Saer. Entre devaluaciones y procesos inflacionarios podríamos decir. ${ }^{3}$

2 Los leminos o lemmini son un grupo de roedores miomorfos conocidos vulgarmente con el nombre de lemmings. Habitan en algunas regiones de Eurasia y en el norte del continente americano, en las tundras, en la taiga y en praderas árticas y se alimentan principalmente de hierbas, raíces y frutos. Este mamífero construye túneles y pozos que le sirven como madriguera y depósito para realizar el aprovisionamiento de alimentos.

3 En su reciente libro, Poéticas impropias. Escrituras argentinas contemporáneas, Nancy Fernández analiza la des-lectura y el descrédito del nombre propio de Saer conjuntamente con la apropiación del nombre propio de Zelarayán como nombre propio faro de las nuevas "generaciones" de escritores. Sin embargo, como bien afirma la crítica argentina, el despojo lingüístico o estético, el maldecir deliberado, la pronunciación maldicha, los errores fónicos u ortográficos no alcanzan para pensar en una dimensión de ruptura con las herencias culturales recibidas (tradiciones). En este sentido, la historia cultural

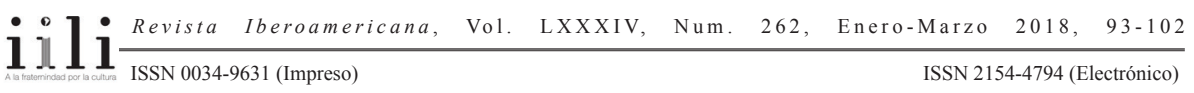


En un reciente ensayo, Mario Cámara sostiene que al narrar sus orígenes como escritor, Martín Gambarotta, autor del libro de poemas Punctum (1995), cuando se refiere a la novela Glosa de Juan José Saer -de quien, según sus palabras, ya había leído y admirado El limonero real, Cicatrices, Nadie nada nunca y La mayor-, lo hace para afirmar que su personaje central, Ángel Leto, se le había hecho "un tanto lejano, un tanto ridículo y afectado". ${ }^{4}$ En el caso de Fabián Casas, forma parte de un incidente, de una pregunta que le hace el protagonista del relato, Sergio Narváez, periodista cultural de la editorial Normas (no confundir el sujeto de la enunciación con el sujeto empírico o autor real, aclara con su cómico gesto pedagógico y populista el narrador del relato), al autor de Comas y más comas y Para una literatura sin botulismos, luego que "el Gran Escritor" que vive en París y viene de visita solo una vez por año a la Argentina, recitara su cantinela o "kata" literaria (Borges, Macedonio, Juan L, Faulkner, Onetti, Musil, Joyce y Kafka), Cualquier similitud con la realidad es pura coincidencia podría decir siguiendo los tics mediáticos de Casas. Dice el texto: "[...] le pregunté si le gustaba Ricardo Zelarayán. Zelarayán?, me dijo. ¿Es un autor argentino? Le dije que sí. Se quedó pensativo un rato largo, mirando la mesa, la tacita blanca de café. Era Anatoli Karpov pensando qué pieza mover. Después agachó la mente, se durmió, roncó, pedorreó" (Casas 45). Quizás la pregunta correcta que tendría que haber hecho Sergio Narváez, dentro del spleen del relato, es si como Haroldo Conti, "el Gran Escritor” (al decir de Casas) alguna vez escuchó a Led Zeppelin.

No haber leído a Zelarayán es sinónimo para Casas de no haber leído poesía y por lo tanto, de ser un analfabeto literario. La crítica por pretender ser demasiado joven para no morir y siguiendo al autor de Tuca u Ocio, ha ocultado este dilema (qué es lo que se lee de Zelarayán y cuáles son los efectos en las escrituras actuales) o ha silenciado el también registro oral y poético en las novelas de Saer, más allá de las disimetrías y poéticas bien diferenciales en el uno y en el otro.

El título del relato de Casas, como sabemos, hace una obvia referencia a una canción del grupo Manal que pertenece al álbum homónimo de $1970 .{ }^{5}$ Bajo la estela, si

siempre oficia como filtro y catalizador de las nuevas experiencias literarias y estéticas. Zelarayán más que intentar torcer las normas de una gramática, más bien propiciaba, a través de la experimentación y la politización del margen, la utopía de una palabra secreta y maldita. Si en muchos casos las escrituras contemporáneas están demasiado cerca del lenguaje "despojado" y pasajero presente visiblemente en los comentarios y los estilos del facebook y el twitter; tampoco suponen un desafío a las reglas que norman los circuitos de producción y circulación del arte. ¿En qué consiste lo publicable y aquello que no lo es?, se preguntaba hace un tiempo Roland Barthes en "Deliberación" en su libro Lo obvio y lo obtuso. Imágenes, gestos, voces 365-380.

4 Cfr. Mario Cámara: "Poesía e historia en Punctum de Martín Gambarotta", en Edgardo H. Berg (2013: 101-102. También ver Jorge Fondenbrider (2006: 238).

5 La canción se suele afirmar, está inspirada en un lugar real, una casa quinta situada en la localidad de Monte Grande, al sur de la ciudad de Buenos Aires. Con cinco pinos a cada lado de la entrada, ese inmueble había sido alquilado por el pintor Roy Mackintosh, con la idea de hacer una de las primeras

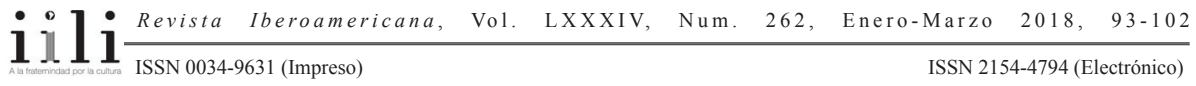


se quiere, de Cream (el trío formado por Eric Clapton, Jack Bruce y Ginger Baker), el longplay fue editado por el sello Mandioca, bajo la tutela de Jorge Álvarez y “Casa con tres pinos" es la sexta canción del álbum compuesta por los ricoteros Javier Martínez, Claudio Gabis y Alejandro Medina (no olvidemos que Ricota fue el primer nombre del grupo antes de su entrada a la industria discográfica, una forma nativa de homenajear y al mismo tiempo parodizar al trío de blues inglés de mediados de los años sesenta). La canción de Manal ya había aparecido citada en los años sesenta, en una novela de Haroldo Conti, más precisamente en la novela En vida (1971). Luego de haberse escapado de la alienante rutina de su trabajo, la sede de una revista de publicidad y en unos de sus vagabundeos por la ciudad de Buenos Aires, Oreste Antonelli escucha por unos altoparlantes la canción, entremezclada por el ruido urbano que lo atormenta. Pero lo que en Conti formaba parte de una poética cercana a la Beat Generation que hacía del nomadismo crónico una forma de protesta y rebelión con las formas injustas y alienantes de la cultura capitalista, podríamos decir; en Casas forma parte de una exhibición irónica para cerrar la conversación y cambiar de tema. El relato paródico del fracaso literario del Gran Escritor, luego de la presentación de su obra por un "guapo" discípulo en un café literario (cualquier similitud con Alan Pauls es pura coincidencia) se muda en la historia distópica y retro-folk del escritor actual. En un café, el café de Norman, mientras Narváez reparte y desparrama a las muchachas presentes los inéditos poemas del Gran Escritor comienza a sonar la canción y Casas reproduce la letra completa, entrecortada por el ruido y el diálogo de los parroquianos. El relato "Casa con diez pinos" nos recuerda por momentos a Asis en sus transgresiones módicas del pícaro urbano en Flores robadas en los jardines de Quilmes (1980) (basta pensar en la inscripción de los soportes verbales del habla popular de capas medias urbanas y ciertos clises del periodismo deportivo, los episodios picarescos que destronan el campo cultural, quizá la foto que Marcelo Zalim, narrador personaje de la novela, obtiene de Borges en un mingitorio, al mejor estilo de un paparazzi, sea el mejor ejemplo), y por momentos a los juegos paródicos de Osvaldo Soriano (aunque en Soriano habría que decir que la parodización del texto social presupone una relectura de la historia nacional o un paso de la épica a la comedia, humana, demasiado humana y en clave nacional), o un poco más cerca, el relato asume, si se quiere, la forma de la historia de un star system en declive, al modo de Historia de Teller (1992) de Jorge Lanata, si se quiere de una estrella del rock decadente y ya viejo, como el autor de Agua viva en el

comunidades hippies de la época. A la casa concurrían artistas como Tanguito, Pajarito Zaguri, Norberto Aníbal Napolitano (Pappo o El Carpo), Miguel Abuelo y Javier Martínez, entre otros. Durante el día, los visitantes ocupaban el parque de una hectárea componiendo música, pintando o dibujando. Por la noche se juntaban en la casa y se mostraban sus obras. En ese contexto bohemio Martínez compuso la canción. "Casa con diez pinos", editado en el Manal (1970) y, años después, en el álbum doble y compilatorio también llamado Manal (1973).

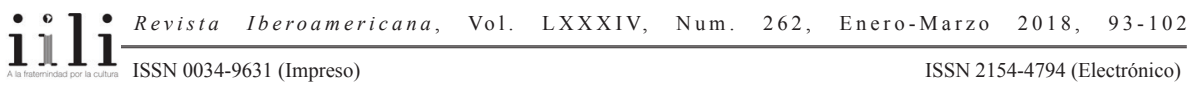


cuento de Casas que entre el sudor y la asfixia se preocupa por el éxito en el mercado de un escritor mexicano autor de libros de autoayuda y de sus porcentajes de ventas.

El otro relato es de Sergio Chejfec y forma parte de una de las nueve historias que componen su último libro, Modo linterna publicado recientemente por la Editorial Entropía. El cuento se llama "Una visita al cementerio" y como los otros relatos del volumen se mueven tensos en la inmadurez de la forma (Gombrowicz 83-85), entre la ficción, la crónica testimonial y el ensayo especulativo. Se trata de una caminata entre pares (un novelista, un ensayista, un teólogo y más tarde se le agrega un músico) por París y una expedición a la tumba de Juan José Saer. Si bien los personajes del cuento pierden referencialidad y asoman como conceptos puros o alegorías, desrealización que es habitual en la novelísitica del autor, podemos suponer (casi con riesgo de traducir los genéricos) que parte de una experiencia real. El trayecto y la expedición, si se quiere, dan forma a una breve y microscópica comedia humana cuyo sentido del final se retrasa y se demora, en banales rodeos y nimias conversaciones peregrinas. El nombre propio o la llegada al Crematorium queda aplazada o en segundo plano. Modo linterna, sabemos, es una aplicación de la telefonía celular pero también una disposición reticular, una forma de mirar: o para decirlo mejor: la microscopía de una glosa que persiste como un resplandor crepuscular. Un ojo que mira puntualmente y recoje a modo de homenaje la forma de la persistente intriga saereana (un grupo de amigos que comparten una caminata por la ciudad, la forma del diálogo como forma de aplazar una experiencia, un narrador un poco afuera del cuadro que escucha el intermitente crepitar de las palabras que van y vienen y sostiene los pases de los registros e instancias de enunciación para recordar brevemente lo imborrable de La vuelta completa o de la propia Glosa). Aplazar el encuentro y leer a contraluz la borroneada inscripción funeraria es también dar vida a esa forma que se mueve como un destino literario, como un paseo o una caminata nunca acabada del todo.

Hace poco vi una película extraordinaria del director húngaro Béla Tarr. La película se llama El caballo de Turín (2011) y como su título lo indica hace referencia a una anécdota sobre la vida de Friedrich Nietzsche. Contada a partir de una voz en off y con un extraordinario plano-secuencia inicial, refiere un incidente personal del filósofo quien al ver un cochero fustigando al caballo que se niega a avanzar, se compadece, abraza al animal y llora. En realidad lo que la voz en off cuenta (el incidente en la vida de Nietzsche antes de su locura y encierro definitivo en Turín) sirve de base para la primera secuencia narrativa donde se ve un anciano con su carro tirado por un caballo hasta llegar a la casa que comparte con su hija, un paraje inhóspito y solitario donde el sigiloso y por momentos disonante silbido del viento es el único elemento perturbador de esas tierras pobres. La película se divide en seis partes que se corresponden a igual número de días consecutivos en la vida de los protagonistas, durante los cuales se repiten más o menos las mismas acciones de su vida cotidiana: la mujer va a buscar

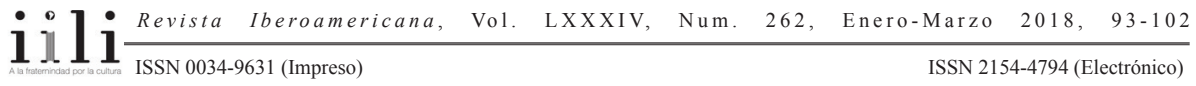


agua al pozo, viste a su padre, cocina las papas que son comidas con las manos. Los dos protagonistas están casi siempre en silencio. Las palabras cobran importancia sólo cuando intervienen agentes externos: el inquietante discurso del visitante de la morada anunciando la ruina de una vecina ciudad, los gritos de los gitanos que se acercan para sacar agua del pozo o se exaltan ante el pretendido y finalmente frustrado rapto de la muchacha, la lectura en voz alta que hace la hija de un libro obsequiado por extraños o cuando la voz en off inserta esporádicamente comentarios sobre los repetitivos hechos. El caballo deja de alimentarse, el pozo se seca, la brasa se consume, la luz del sol deja de brillar. Una misma pieza musical aparece y desaparece en variadas intensidades y acompaña largos planos-secuencias en blanco y negro que nos interrogan sobre ese tiempo de la espera. La incógnita que plantea el filme es lo que viene después. ¿Qué forma tendrá esa historia? ${ }^{6}$

En nuestra época de comunicaciones rápidas y veloces, de información intempestiva y fulminante, la gravitación de la tecnología vinculada a los nuevos modos de circulación y recepción de la cultura nos hace ver la literatura del presente como si hubiese entrado en un nuevo estadio o se encaminara veloz a su propia disolución.

El quiebre epistémico que significaron las vanguardias históricas en la contemporaneidad hacen saltar por el aire el engaño de la pura autonomía (y consecuentemente de la posautonomía). La literatura y el arte en general no sólo se definen históricamente por sus fluencias transgenéricas, ni por sus migraciones y prácticas de fusión discursivas, ni tampoco por la escenificación y la teatralización de los nuevos soportes mediáticos. En tanto inscripción de su propia incompletud (work in progress) y como experiencia de lo comunicable, la literatura, en más de una ocasión, ha sido definida por fuera de sus dominios. Y como sabemos, en distintos momentos y períodos históricos, su real eficacia social ha sido, la mayoría de las veces, mediata y extemporánea. ¿Qué puede haber en los sucesivos anuncios acerca de la desaparición de la literatura sino ciertas metamorfosis en sus modos de escritura-lectura?

\footnotetext{
6 Tomo prestadas algunas reflexiones del último ensayo de Jacques Rancière a propósito de la producción cinematográfica del realizador húngaro Béla Tarr. Deteniéndose en el filme "El caballo de Turín" (2011), Rancière afirma: "El 'Último film', dice Béla Tarr. No entendemos con ello el filme del fin de los tiempos, la descripción de un presente más allá del cual ya no hay más futuro que esperar. Más bien es el film antes del cual no es posible regresar: el que lleva el esquema de la repetición interrumpida a sus elementos primarios y la lucha de cada ser contra su destino a su último punto de apoyo y que, al mismo tiempo, hace de cualquier otro filme sencillamente un filme más, un injerto más del mismo esquema en otra historia. Haber hecho su último filme no es entrar forzosamente en el tiempo en que ya no es posible filmar. El tiempo después del final es más bien aquel donde se sabe que en cada nuevo filme se planteará la misma pregunta: ¿por qué hacer un filme más sobre una historia que, en su principio, es siempre la misma? Podríamos sugerir que es porque la exploración de las situaciones que esa historia idéntica puede determinar es tan infinita como la constancia con la que los individuos se dedican a soportarla. La última mañana es todavía una mañana previa y el último filme todavía es un filme más. El círculo cerrado está siempre abierto" (Rancière 84-85).
}

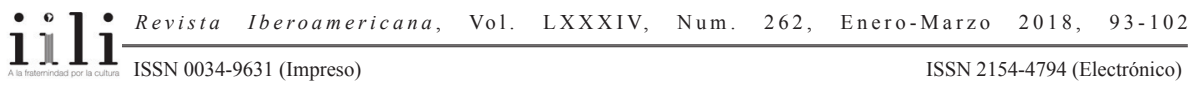


O como me sugirió Jorge Wolff, preanunciado en el acápite inicial de estas notas, la pregunta que apuesta a la verificación de lo inverificable, está en las palabras que escribió Giorgio Agamben a propósito de lo contemporáneo:

[...] contemporáneo es aquel que tiene la mirada fija en su tiempo, para percibir no la luz sino la oscuridad. Todos los tiempos son, para quien experimenta la contemporaneidad, oscuros. Contemporáneo es, justamente, aquel que sabe ver esta oscuridad, y que es capaz de escribir mojando la pluma en las tinieblas del presente. (Agamben 62-63)

Es verdad, como alguna vez dijo Nicolás Rosa (1997: 73), el hombre pudo no haber escrito nunca y por ende no haber leído jamás. El chat, los emails, la aplicación del WhatsApp, los formatos egocéntricos y por momentos autistas de Facebook, los Twitts y las actuales tecnologías de comunicación inciden en nuestra vida cotidiana y articulan nuevas formas de experiencia pero suelen ocultar las intrigas y los misterios de la escritura. Si se quiere, una forma de decir.

\section{BiBLIOGRAFÍA}

Adorno, Theodor W. Teoría estética. Buenos Aires: Orbis, 1983.

Asis, Jorge. Flores robadas en los jardines de Quilmes. Buenos Aires: Losada, 1980. Agamben, Giorgio. O que é o contemporâneo e outros ensaios. Vinícius Honesko, trad. Chapecó: Argos, 2009.

Bajtín, Mijaíl. “Epopeya y novela”. Revista Eco 195 (1978): 283-300.

Barthes, Roland. Lo obvio y lo obtuso. Imágenes, gestos, voces. Buenos Aires: Paidós, 1986.

Berg, Edgardo H., coord. Papeles en progreso II. Usos y relectura de Papeles en progreso II: usos y relectura de la tradición en la literatura argentina. Mar del Plata: Universidad Nacional de Mar del Plata, 2013.

Borges, Jorge Luis. "El escritor argentino y la tradición”. Discusión. Buenos Aires: Emecé, 1982. 151-162.

“Kafka y sus precursores”y "Nueva refutación del tiempo". Otras inquisiciones.

Buenos Aires: Emecé, 1986. 137-140 y 219-241.

El caballo de Turín. Béla Tarr, dir. TTFilmmûhely, 2011.

Cámara, Mario. "Poesía e historia en Punctum de Martín Gambarotta", en Berg, Edgardo H. (Coord.) Papeles en progreso II. Usos y relectura de Papeles en progreso II: usos y relectura de la tradición en la literatura argentina. Mar del Plata: Universidad Nacional de Mar del Plata, 2013. 99-114.

Casas, Fabián. Los Lemmings y otros. Buenos Aires: Santiago Arcos Editor, 2005.

Conti, Haroldo. En vida. Buenos Aires: Seix Barral, 1971.

Chejfec, Sergio. Modo linterna. Buenos Aires: Editorial Entropía, 2013. 
Deleuze, Gilles. “¿Qué es una literatura menor?” Kafka. Por una literatura menor. México: Era, 1978. 28-44.

Fernández, Nancy. Poéticas impropias. Escrituras argentinas contemporáneas. Mar del Plata: Universidad Nacional de Mar del Plata, 2013.

Fondenbrider, Jorge, comp. Tres décadas de poesía argentina. Buenos Aires: Eudeba, 2006.

Gambarrota, Martín. Punctum. Buenos Aires: Ed. de Tierra Firme, 1995.

Gombrowicz, Witold. Ferdydurke. Buenos Aires: Sudamericana, 1964.

Gramsci, Antonio. Literatura y vida nacional. México: Juan Pablos Editor, 1998.

Gramuglio, María Teresa. "Las aventuras del orden: Juan José Saer, Cicatrices. Revista Los Libros 3 (septiembre 1969): 5 y 24.

"El arte de narrar". Punto de Vista 6 (julio 1979): 3-8.

"La filosofía en el relato (sobre El entenado). Punto de Vista 20 (mayo 1984):

35-36.

“El lugar de Saer”. Juan José Saer por Juan José Saer. Jorge Lafforgue, ed. Buenos Aires: Celtia, 1986. 261-299.

Lanata, Jorge. Historia de Teller. Buenos Aires: Planeta, Biblioteca del Sur, 1991.

Ludmer, Josefina. "Literaturas postautónomas". Ciberletras. Revista de crítica literaria y de cultura 17 (2007). <http://www.lehman.cuny.edu/ciberletras>. Aqui América latina. Una especulación. Buenos Aires: Eterna Cadencia, 2010.

Martínez Estrada, Ezequiel. Para una revisión de las letras argentinas (prolegómenos). Buenos Aires: Losada, 1967.

Piglia, Ricardo. “Sobre La mayor". Punto de Vista 3 (julio 1978): 18-19. "Literatura y tradición. El tenso músculo de la memoria". Página 30 (enero 1991): 59-62.

“La música de Saer". Página 12: Primer Plano (25 septiembre 1994): 3.

“El lugar de Juan José Saer”. El lugar de Piglia. Crítica sinficción. Jorge Carrión, comp. Barcelona: Candaya, 2008. 162-188.

Rancière, Jacques. Béla Tarr: después del final. Buenos Aires: El Cuenco de Plata, 2013. Rosa, Nicolás. Artefacto. Rosario: Beatriz Viterbo, 1992.

La lengua del ausente. Buenos Aires: Biblos, 1997.

Usos de la literatura. Valencia: Tirant lo Blanch Libros/Universitat de Valencia, 1999.

Saer, Juan José. La vuelta completa. Rosario: Biblioteca Popular Constancio C. Vigil, 1966.

El limonero real. Buenos Aires: CEAL, 1976.

Nadie nada nunca. México: Siglo Veintiuno, 1980.

La mayor. Buenos Aires: CEAL, 1982.

Cicatrices. Buenos Aires: CEAL, 1983.

Glosa. Buenos Aires: Alianza, 1986.

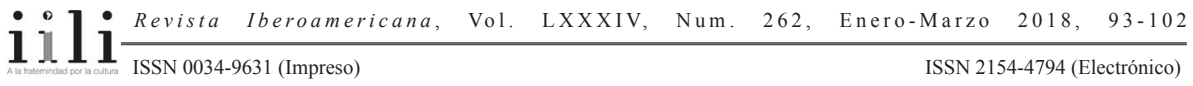


Sarlo, Beatriz. "Tres novelas argentinas. Saer-Tizón-Conti". Revista Los Libros 44 (febrero 1976): 3-6.

"Narrar la percepción". Punto de Vista 10 (noviembre 1980): 34-37.

"La condición mortal". Punto de Vista 46 (agosto 1993): 28-31.

Escritos sobre literatura argentina. Buenos Aires: Siglo Veintiuno Editores, 2007.

Zelarayán, Ricardo. Roña criolla. Buenos Aires: Libros de Tierra Firme, 1991. La piel de caballo. Buenos Aires: Adriana Hidalgo, 1999.

"La obsesión del espacio (1972)". Ahora o nunca. Poesía reunida. Buenos Aires: Argonauta, 2009. 